\title{
As transformações do organicismo e do conceito de motivo na teoria schenkeriana
}

The transformations of organicism and the concept of motif in Schenkerian Theory

Rafael Moreira Fortes ${ }^{1}$ Universidade Federal do Piauí for.rafael@gmail.com 


\section{Resumo}

Este artigo elabora uma leitura sobre a trajetória da teoria schenkeriana: das reflexões sobre a linguagem e a genealogia da música no artigo de 1895, Der Geist der Musikalischen Technik, até a expressão derradeira de sua metodologia analítica em 1935, em Der Freie Satz. Reúne as questões que motivaram o desenvolvimento dessa teoria, dando especial enfoque às transformações do conceito de motivo e das metáforas organicistas. Observa como esses dois aspectos são desenvolvidos conjuntamente ao longo de 40 anos de produção teórica, demonstrando a íntima conexão entre aspectos técnicos e teóricos. A resolução de problemas, como a causalidade musical e a associação de ideias em sua teoria, é investigada à luz desses aspectos, motivando reflexões epistemológicas e filosóficas sobre o desenvolvimento da complexa musicologia de Schenker. $\mathrm{Na}$ exposição desta trajetória, o artigo se depara com diversas questões-chave que compreendem e antecipam o posterior desenvolvimento do método que denominamos hoje em dia como Análise Schenkeriana. Busca-se, com essa exposição, fomentar um diálogo mais complexo da teoria schenkeriana, tanto com o neo-schenkerianismo quanto com correntes do pensamento além do âmbito musicológico.

Palavras-chave: Análise Schenkeriana. Teoria Musical. Filosofia da Música. Epistemologia. .

\section{Abstract}

This article elaborates a view about Schenkerian's Theory trajectory: from its thoughts about language and musical genealogy in the 1895's article, Der Geist der Musikalischen Technik, until the final expression of the analytical methodology in 1935, on Der Freie Satz. It reunites the issues that motivated the development of that theory, with special focus to the concept of motif's and the organicist metaphor's transformations. It observes how these two aspects are developed conjunctly throughout 40 years of theoretical publications, showing the intimate connection between technical and theoretical aspects. The resolution of problems such as the musical causality and the association of ideas is investigated within those aspects, promoting philosophical and epistemological thoughts about the development of Schenker's complex musicology. Exposing this trajectory, the article finds many keyissues that comprehend and anticipates the posterior development of what we call today as Schenkerian Analysis. This exposition seeks to foment a more complex dialog with neoschenkerianism, but also with streams of thought that go beyond musicology.

Keywords: Schenkerian Analysis. Musical Theory. Philosophy of music. Epistemology.

1 Professor adunto na Universidade Federal do Piauí (UFPI). Doutor em Musicologia pela Universidade Federal do Estado do Rio de Janeiro (UNIRIO, 2016-2020). Mestre em Música na área de poéticas da criação musical pela Universidade Federal do Rio de Janeiro (UFRJ, 2014-2016). Graduado em Música com especialização em composição pela Universidade Federal do Estado do Rio de Janeiro (UNIRIO, 2010-2013). 


\section{Introdução}

No prefácio da edição americana de Harmonielehre (1968 [1906]), Oswald Jonas compreende as obras iniciais de Schenker como estágios embrionários do desenvolvimento de sua teoria. Segundo o comentador, a teoria schenkeriana é o resultado de um longo processo que encontrará sua expressão definitiva apenas em Der Freie Satz (1979 [1935]). Em suas palavras, é um processo em que "certos estágios de sua obra, embora cada um deles constitua uma base essencial para as construções subsequentes, se tornaram, em certos aspectos, obsoletos quando a obra final apareceu" (SCHENKER, 1968 [1906], p.V, grifo nosso). A postura de Jonas é compatível com o processo de adaptação acadêmica da obra de Schenker, em que se deu primazia ao desenvolvimento do método analítico em detrimento dos aspectos psicológicos, metafísicos, culturais, teológicos etc. presentes em sua obra. ${ }^{2}$

Contrariamente a essa postura, este artigo comenta a teoria schenkeriana não como uma metodologia estabelecida, mas como uma série de epifanias e conquistas teóricas que se consolidaram ao longo de mais de 40 anos de produção. Dentre outras inquietações, é uma teoria que surge a partir da crítica ao caráter abstrato e especulativo das teorias a ela contemporâneas, propondo em contrapartida a direta observação das obras dos antigos mestres. Esse aspecto pode ser observado na expressiva quantidade de exemplos musicais que o autor comenta/analisa e em suas críticas à utilização de harmonizações de corais a quatro vozes como ferramentas didáticas.

Segundo Boucquet (2005, p.200), a atitude crítica de Schenker qualifica seu trabalho como o de um "anti-teórico" que poderia ao mesmo tempo ser considerado um "teórico por excelência", 3 o que se reflete também na autocompreensão de Schenker de seu trabalho como mais artístico do que científico. ${ }^{4} \mathrm{O}$ epíteto de "anti-teórico" se deve à sua constante denúncia da distância entre teoria musical e processo composicional. Schenker critica essas teorias como um conjunto de saberes que não respondem as perguntas fundamentais sobre o processo de criação artística, mas apenas relatam o objeto depois de estabelecido. Nesse sentido, ele se interessa mais pela dinâmica da criação artística do que pela descrição dos aspectos que compõem as estruturas musicais - postura que aponta para a necessidade de atribuir aspectos dinâmicos, sistêmicos e vitais à análise dessas estruturas. Em outras palavras, Schenker se interessa por aspectos "fisiológicos" do "organismo" musical em vez dos aspectos "anatômicos".

A partir dessas críticas, Schenker procura questionar e revisar os elementos da teoria musical, mudando o foco de sua inquirição. Essa atitude remete à ambição de um projeto teórico que busca oferecer uma "teoria unificada da música" (BOUCQUET, 2005, p.200): uma teoria que prescinda de terminologias historicamente determinadas e que reformule

2 No que Rothstein (1990) denomina como o processo de "americanização" de Schenker.

3 Boucquet qualifica a teoria de Arnold Schoenberg da mesma forma, ao comparar o trabalho dos dois pensadores.

4 "Eu estou profundamente ciente de que minha teoria, como foi extraída dos próprios produtos da genialidade artística, é e deve permanecer uma arte, e, portanto, nunca se transformar em uma ciência". Original: "I am keenly aware that my theory, extracted as it is from the very products of artistic genius, is and must remain itself an art, and so can never become 'science'"' (SCHENKER, 2014c [1930], p. 54). 
todos os aspectos musicais a partir de uma nova perspectiva. Schenker parece se questionar: "como falar de procedimentos complexos, como, por exemplo, um cânon retrógrado e invertido, se não sabemos ainda o que é uma tríade?". Em outras palavras, sua teoria revê os pressupostos da teoria musical elementar de modo a observar de uma nova maneira as estruturas mais complexas: ela refaz as perguntas mais simples para obter novas respostas sobre pressupostos teóricos consolidados.

Tal postura é acompanhada de noções singulares sobre a história da música que buscam reformular as questões originárias. Para Schenker, elas devem referir-se antes de tudo à historicidade interna do objeto musical, à série de eventos que o próprio sistema desenvolve independentemente das culturas e períodos em que foram realizados. O sincronismo almejado em relação à história musical, considerada como fator externo, é contraposto ao desejo de criar uma espécie de genealogia do "espírito" do tonalismo. Schenker apresenta a inquietação teórica de descrever uma dialética própria das transformações tonais em sua temporalidade independente. Nesse sentido, o autor perfila uma série de perguntas que deveriam nortear o tipo de pesquisa almejada:

\begin{abstract}
Quando e como a lei da consonância (a partir da oitava, quinta e terça) pela primeira vez desenvolveu seu caminho e preencheu-se a si mesma em sucessões de tons (compreendidos horizontalmente), de modo que as sucessões tonais, já que expressam uma tríade, poderiam ser experienciadas como uma unidade? Isso ocorreu antes mesmo das tentativas iniciais da polifonia ou depois? Como pensar o desenvolvimento da Urlinie paralelo a esse processo em que a consonância pela primeira vez impregnou secretamente a dimensão horizontal? ${ }^{5}$ (SCHENKER, 2004 [1921-1923], p.52, tradução nossa).
\end{abstract}

De acordo com essas considerações, este artigo revisa e comenta a trajetória da teoria schenkeriana, apontando as contradições e os meandros desse percurso. Mostra como o tom de seus escritos iniciais é transformado na medida em que o método analítico vai gradualmente sendo elaborado, como as problematizações teóricas iniciais, que levam a aporias e negações extremas (como sua postura anti-organicista), são substituídas posteriormente por um tom profético, amparado na crença de sua metodologia. É um processo que reflete a relação de Schenker com o ambiente musicológico, no qual primeiramente ele busca se estabelecer replicando visões e demonstrando influência de outros autores ${ }^{6}$ (embora já apresentando originalidades) e posteriormente apresenta um vocabulário conceitual próprio. Apresenta também as questões de início de sua carreira que parecem ter permanecido no decorrer de sua obra e que fundamentam a inquietação de seu projeto teórico derradeiro, especialmente a questão da causalidade musical e suas implicações organicistas.

\footnotetext{
5 Original: "When and how did the law of consonance (with the octave, fifth, and third) first work its way into and fulfill itself in successions of tones (regarded horizontally), so that the tonal successions, because they expressed a triad, could be experienced as a unit? Did this occur even before the initial attempts at polyphony, or later? How about the Urlinie around the time consonance first secretly impregnated the horizontal dimension?".

6 Ver, por exemplo, em Der Geist der Musikalischen Technik [1895], visões relacionáveis à visão formalista de Eduard Hanslick, além de relações com David Hume e Ernst Mach, como aponta Korsyn (1993).
} 


\section{A causalidade musical em Der Geist der Musikalischen Technik [1895]}

Em Der Geist der Musikalischen Technik (daqui em diante, Geist), Schenker desenvolve uma genealogia sobre o desenvolvimento da música ${ }^{8}$ que compreende o formalismo como a mais avançada dentre três etapas: 1) a expressão de sentimentos e emoções, 2) a imitação da linguagem e 3) a repetição de motivos. Essas etapas procuram descrever o trajeto que "separa a música de uma real ou imaginada emoção ou sensação e a estabelece por sua vez no enraizamento de um desejo de atividade puramente interno"9 (2007 [1895], p.320, grifo nosso), atividade que também é denominada como o "princípio formal da criação" (2007 [1895], p.320). A genealogia é marcada pela série de eventos que permitiriam à música tornar-se independente, regida por suas próprias normas internas - uma série de eventos em que as sensações que representa se tornam não mais a causa única, mas uma consequência ulterior de sua organização com seus próprios materiais.

A relação com a linguagem é fundamental nessa trajetória. Schenker observa que a interdependência com o texto própria da música vocal permitiu em um primeiro momento que a música imitasse a lógica da organização formal da linguagem. A função da música seria a de reforçar o caráter e o ânimo do texto, mas nesse ato acabaria também emulando aspectos formais do próprio pensamento. Em suas palavras, a música "teve que aprender a sugerir de forma convincente a impressão de um pensamento autocontido. Por meio de sua associação com a linguagem, a música aprendeu a imitar acuradamente todas as vicissitudes do pensamento - sua ambição, sua auto-organização, suas resoluções [...]"10 (SCHENKER, 2007 [1895], p.320, grifo nosso). Nesse processo, a música imitaria apenas a aparência da lógica do pensamento, ou seja, seus aspectos não significativos e externos, como sua rítmica e suas relações de oposição. Ela não possui a capacidade de associação de ideias intrínseca à linguagem, já que não "representa objetos e conceitos por si mesma" (SCHENKER, 2007 [1895], p. 321), mas pode emular o seu comportamento em um sentido puramente formal.

$\mathrm{Na}$ etapa final dessa genealogia, a autonomia em relação à linguagem é possibilitada pelos processos de repetição. A concatenação linear das palavras em uma narrativa opõe-se ao aspecto recursivo da técnica imitativa. Schenker argumenta que, diferentemente das "artes que representam ou se relacionam com uma história, [que] não tem razão para repetir motivos individuais"11 (SCHENKER, 2007 [1895], p.321), na música há o retorno às unidades de base em um processo no qual elas são aumentadas, diminuídas, recortadas, embaralhadas

7 O Espírito da Técnica Musical.

8 Da música de concerto europeia, que em sua visão eurocêntrica constitui a arte musical como um todo.

9 Original: "[...] separates music from an actual or imagined emotion or sensation and establishes it instead on the footing of a purely internal desire for activity. I should like to call this the formal principle of creation".

10 Original: "[...] It had to learn to suggest convincingly the impression of self-contained thought. Through its association with language, music learned to mimic accurately all of thought's vicissitudes-its striving, its self-organization, its closure".

11 Original: "Clearly, all the arts that relate or represent a story have no reason to repeat individual motives". 
etc. Assim, os motivos são análogos às palavras apenas na medida em que são as unidades mínimas de referência na construção artística. A repetição é o que diferencia o aspecto circular e recursivo da música do aspecto linear da linguagem. ${ }^{12}$

A situação de orfandade da música em relação à linguagem, isto é, a separação de seu modelo de referência, é descrita por Schenker como uma "deficiência". Sua visão aponta para a relação hierárquica entre o logos, representado pela linguagem, e a música, que nesta dicotomia representa o polo sensível. $O$ entendimento suscitado pela música é apresentado como algo de segunda ordem, fruto de pontuais associações motívicas e tonais, enquanto na linguagem o entendimento emerge para planos consolidados, nos quais o pensamento de fato se estabelece e é elaborado.

As pessoas devem ter ficado completamente convencidas desta deficiência por parte da música assim que a música instrumental começou a surgir. Durante o tempo em que a música se mesclou à linguagem, fez acreditar a si mesma que era compreensível, embora fosse apenas a linguagem que assegurasse a compreensibilidade; mas, quando se aventurou lá fora sozinha no mundo, deve ter percebido seu autoengano um tanto rapidamente e reconhecido sua inabilidade de solicitar entendimento em qualquer outro modo que não a clarificação dos motivos e sucessões tonais por meio de repetições e imitações.13 (SCHENKER, 2007 [1895], p.321, grifo nosso).

Neste ponto, Geist apresenta um dos principais problemas que o projeto schenkeriano como um todo procura resolver: como a música pode ser uma arte linear e causal? Pois, embora seja uma arte que se apresenta num lapso temporal, para o autor, nada parece garantir a necessidade lógica de que um determinado evento musical seja sucedido de um outro. Enquanto na linguagem as concatenações ilógicas e aleatórias de palavras são claramente identificadas e apontadas como erros gramaticais, na música esses "erros" não são evidentes. Schenker parece se perguntar: quais aspectos garantiriam que a união de motivos possuiria uma necessidade lógica para ser apresentada na forma que de fato se deu? Mais amplamente, como se dão as relações de causalidade na música? Se forem inerentes ao objeto musical, como apontar a estrutura dessa causalidade? E, se não o forem, resultariam apenas da recepção por parte do ouvinte em um processo cognitivo de ordenação?

A partir dessas indagações, o autor realiza a crítica à metáfora organicista como um todo, apresentando visões surpreendentes se comparadas à sua postura no restante de sua produção teórica. ${ }^{14} \mathrm{~A}$ crítica à metáfora organicista baseia-se na constatação da artificialidade do procedimento artístico e pode ser identificada já na dialética sugerida pelo título do ensaio entre os termos espírito [Geist] e técnica [Technik], ou seja, entre os aspectos metafísicos

12 Por outro lado, a poesia seria então a arte da linguagem que toma como modelo a música, que imita os procedimentos de repetição e recursividade a ela inerentes.

13 Original: "People must have become thoroughly convinced of this deficiency on the part of music as soon as instrumental music began to arise. For as long as music clung to language, it believed itself to be comprehensible, although it was only language that ensured comprehensibility; but when it ventured out alone into the world, it must have realized its self- deception rather quickly and recognized its inability to solicit understanding in any other way than by clarifying individual motives and tonal successions through repetition and imitation".

14 Inicia-se, assim, a trajetória que o musicólogo William Pastille denomina como a do autor anti-organicista para o arqui-organicista (1984, p.32). 
e artificiais em jogo no processo composicional. Em meio a essa artificialidade, as imagens orgânicas buscam expressar sentido e ordem de um modo que parece fictício e alheio à obra. Nas palavras do autor, essas imagens expressam um "ilusório halo de lógica racional", ou seja, uma impressão ilusória proveniente do repertório técnico dos compositores.

Um ilusório halo de lógica racional começou a brotar de todas as estruturas elaboradas pelos esquemas artificiais da imaginação, e não demorou muito para que as pessoas começassem até a acreditar que as construções artificiais têm o mesmo tipo de necessidade possuída por organismos naturais. ${ }^{15}$ (SCHENKER, 2007 [1895], p.328, grifos nossos).

Sua argumentação é separada em dois questionamentos principais. O primeiro questionamento se refere à relação com a valoração. A denominação de uma peça musical como orgânica está sempre relacionada com a atribuição de um valor positivo em sua apreciação. Mas por que razão, pergunta-se o autor, uma peça considerada ruim não pode ser orgânica? Segundo Schenker, a própria formulação da questão já responde parte da pergunta. Se a música considerada de qualidade é necessariamente orgânica, "então fica claro que nós estamos transferindo o suposto charme do orgânico ao conteúdo que transmitiu esta espécie de charme"16 (2007 [1895], p.328). Segundo esse questionamento, o termo funciona como um conceito vazio, aplicável em qualquer contexto em que haja prazer, sem implicar necessariamente alguma característica identificável, mas apenas uma projeção subjetiva por parte do ouvinte. Schenker critica o uso do termo orgânico sem implicação direta na avaliação da estruturação musical como uma mera adjetivação. Isso resulta em sua dependência da agradabilidade, ou seja, em um juízo estético baseado unicamente em aspectos sensíveis, e por isso subjetivo e relativo.

O segundo questionamento diz respeito à relação de causalidade melódica. De acordo com o Schenker de Geist, a construção melódica possui sempre múltiplas possibilidades sequenciais, de modo que nunca se poderia dizer que apenas um resultado estaria predeterminado pelas características do material. As inúmeras possibilidades de sequenciação, observadas nos estudos de rascunhos dos compositores, comprovariam que a escolha das partes componentes de uma melodia é eventual e resultante de escolhas subjetivas, e não uma necessidade imanente ao material. São escolhas realizadas em meio ao mosaico de possibilidades gerado nos processos artificiais/técnicos de elaboração. Na decisão final sobre a estrutura melódica, "já que ele selecionou apenas uma opção, nós não podemos saber que outros materiais estavam disponíveis para ele [...], mas apenas aquele que mais lhe agradou pessoalmente" (2007 [1895], p.328). Assim, a imagem do compositor como um sonâmbulo (1968 [1906], p.60), guiado pelas necessidades da natureza tonal, é precedida na trajetória da teoria schenkeriana pela de um racional construtor de estruturas musicais que "extrai de sua imaginação similaridades e contrastes variados, de modo a finalmente selecionar a

15 Original: "And in this way an illusory halo of rational logic began to shine over all the structures elaborated by the artificial designs of the imagination, and it did not take long before people even began to believe that the artificial constructs had the same sort of necessity possessed by natural organisms".

16 Original: "Then it is all too clear that we are here transferring the supposed charm of the organic to the content that has imparted that sort of charm". 
melhor opção"17 (2007 [1895], ${ }^{18}$ p.328). A partir dessas reflexões, Schenker conclui que, "de fato, nenhum conteúdo musical é orgânico. Falta a ele qualquer princípio de causalidade, e a inventada melodia nunca possui uma determinação tão resoluta que poderia dizer 'apenas esta melodia, e nenhuma outra, pode me seguir'"19 (2007 [1895], p.328, grifo nosso). Nesse sentido, o autor ainda questiona: "Também não é correto, eu acho, assumir que o estado $B$ sucedeu o estado A organicamente só porque B foi diretamente designado para seguir A diretamente em um ponto determinado"20 (2007 [1895], p.329, grifo nosso).

Nessas argumentações, Schenker procura distinguir entre sucessão e causalidade: um evento suceder o outro não implica ter sido causado por ele. A preocupação em definir a diferença entre esses dois tipos de relação demonstra a inquietação que mais tarde será resolvida em sua teoria, principalmente com o conceito de Urlinie, e é significativa da importância da questão da causalidade musical nesses desenvolvimentos posteriores.

Subjacente a esses argumentos reside, portanto, uma desconfiança em relação ao nexo causal em música. A técnica composicional é retratada como um ilusionismo no qual a sensação de organicidade emerge como uma simples tendência cognitiva ou como convenção social. Na visão de Schenker, para se compreender a arte musical com objetividade, deve-se estar atento para não se deixar enganar pelos dispositivos da artificialidade, que deixariam o musicólogo desprevenido e desatento para uma observação consciente.

Segundo Pastille,

A objeção de Schenker ao organicismo na música tem dois fundamentos: em primeiro lugar, que as obras de arte não têm uma lógica intrínseca, e nenhum princípio de causalidade - o que é essencial à noção de organicismo; em segundo lugar, que a organização subjetiva do compositor dos materiais musicais destruiria qualquer lógica musical intrínseca, se tal coisa existisse. ${ }^{21}$ (PASTILLE, 1995, p.1).

Esses questionamentos apontam a seguinte aporia: não se pode falar de uma lógica intrínseca ao material musical se a subjetividade do compositor é quem de fato decide a sucessão dos eventos. A lógica não seria imanente aos materiais, mas fruto de convenções sociais por parte tanto das artificialidades composicionais quanto das ordenações subjetivas dos ouvintes. Não existe nenhuma propriedade intrínseca ao objeto musical que confira a ele impulsos e necessidades imanentes, a partir dos quais ele próprio se expressaria. Assim, não haveria de fato sentido pensar que uma música pode ser orgânica e, consequentemente, não se deveria utilizar organismos como metáforas no entendimento de sua construção.

\footnotetext{
17 Original: "Obtain from his imagination a variety of similarities and contrasts, in order ultimately to select his best option".

18 Daqui em diante, nesta seção, todas as referências sem data referem-se a esta publicação.

19 Original: "As a matter of fact, no musical content is organic. It lacks any principle of causation, and a contrived melody never has a determination so resolute that it can say, 'Only that particular melody, and none other, may follow me'".

20 Original: "It is also not right, I think, to assume that mood B follows mood A organically just because B was directly appointed to follow A directly at a certain point $[\ldots]^{\prime \prime}$.

21 Original: "Schenker objected to organicism in music on two grounds: first, that music artworks had no intrinsic logic, and no principle of causality - which is essential to the notion of organicism; second, that the composer's subjective organization of musical materials would destroy any intrinsic musical logic, if such a thing existed".
} 
Concordando com Pastille, o musicólogo Kevin Korsyn aponta que o ceticismo em relação à causalidade musical expresso em Geist não procura reduzir a música à mera incoerência. É um ceticismo que "toma consciência de que a unidade é sempre relativa e provisória; que obras de arte ocultam, mas não transcendem o artifício; e que não podem atingir a espécie de necessidade natural que o pensamento organicista demanda da arte"22 (KORSYN, 1993, p.102). A artificialidade do objeto musical seria, portanto, avessa a qualquer possibilidade de organicismo. O Schenker de Geist estabelece os fundamentos de uma visão pragmática: não se deve possibilitar uma metáfora como pressuposto lógico, como algo que guie o pensamento acerca de uma construção artificial humana. Não sendo racional, o organicismo é contraproducente.

Korsyn aponta nesse contexto para os paralelos entre a rejeição da causalidade musical no Schenker de Geist e o ceticismo na filosofia empirista de David Hume ${ }^{23}$ (1993, p.113). Há uma passagem deste último que explicita bem esses paralelos. Argumentando sobre a primazia da experiência em relação aos raciocínios a priori na formação do entendimento humano, o filósofo escreve:

Numa palavra, então, todo efeito é um evento distinto de sua causa. Ele não poderia, portanto, ser descoberto na causa, e a primeira invenção ou concepção dele, a priori, deve ser inteiramente arbitrária. E, mesmo depois de ele ser sugerido, a conjunção dele com a causa deve parecer igualmente arbitrária, uma vez que sempre há muitos outros efeitos que, para a razão, devem parecer tão completamente consistentes e naturais como aquele. Em vão, portanto, pretenderíamos determinar qualquer evento singular, ou inferir qualquer causa ou efeito, sem o auxílio da observação e da experiência. (HUME, 2010 [1748], p.169).

A suspeita da relação entre causa e efeito em Hume ressoa na crítica de Schenker ao organicismo. É uma suspeita relacionada à noção dos saberes como construções limitadas pela condição empírica do entendimento humano. Para o Schenker de Geist, as imagens organicistas não sobrevivem ao escrutínio da razão, já que se baseiam em experiências subjetivas compartilhadas por determinados indivíduos e culturas, e não em relações de ideias puras. Mais especificamente, a suposta metafísica que seria induzida de uma obra musical a partir das relações de causa e efeito não passa de uma coleção de técnicas composicionais com o intuito de simular a causalidade vital. Uma pesquisa musicológica séria não cairia nas fáceis ilusões das imagens orgânicas, assim como em Hume as ilusões do racionalismo não iludiriam a inquirição filosófica que suspeita do aparato cognitivo limitado que as emite.

Na leitura de Geist, de acordo com essas ressonâncias da filosofia empirista, o organicismo é tido como uma imagética que procura gerar unidade e coerência para um universo criativo no qual atuam forças não acessíveis ao musicólogo (ou ao menos não acessíveis para

22 O capítulo de Whittle (1993, p.315-396) e a seção de Korsyn (1993, p.95-104) sobre a influência de Nietzsche nos escritos de Schenker adquirem especial relevância na leitura de Geist. 0 cotejamento com o artigo "Sobre a verdade e a mentira no sentido extramoral" (2001), não realizado pelos autores, abre um caminho interessante de investigação.

23 O autor procura embasar esta comparação supondo uma possível influência de Ernst Mach (que, por sua vez, expressa diretamente a influência de Hume em seu trabalho) no pensamento de Schenker. Esta suposição é reforçada historiograficamente por meio de uma carta enviada a Schenker, na qual Mach aponta interesse no trabalho de Schenker, e também a partir da constatação da grande influência do trabalho de Mach no círculo intelectual vienense da virada do século XIX para o século XX. (1993, p.109-116) 
o Schenker de então). É um conjunto de imagens vazias por não terem como suporte um sistema de pensamento que de fato confira a elas legitimidade. Pelo contrário, servem apenas como embelezamentos da linguagem. Nesse sentido, a transição apontada por Pastille (de anti para arqui-organicista) é a de um autor que se deparou com um problema, a vagueza das imagens do orgânico, fundamentou-o e posteriormente desenvolveu a metodologia para solucioná-lo.

A negação do organicismo em Geist ressoa em toda a produção posterior de Schenker. Segundo Cook, Geist "antecipa o trabalho da vida de Schenker em um grau impressionante, [...] identifica o terreno no qual a teoria posterior opera, revela os problemas para os quais a teoria posterior apresenta as soluções"24 (2007, p.63). Com o ímpeto de negar o ceticismo por ele mesmo apresentado, Schenker passa os próximos 40 anos de sua vida (entre 1895 e 1935) procurando conferir legitimidade e suporte para embasar com propriedade as imagens organicistas no âmbito musical.

\section{O motivo como entidade musical em Harmonielehre [1906]}

Em Harmonielehre [1906], o conceito de motivo é apresentado como a solução para os problemas da causalidade e da associação de ideias na música:

Quando pode a música tomar para si a possibilidade de associação de ideias, já que não é dada pela natureza? [...] O motivo, e apenas o motivo, cria a possibilidade de associação de ideias, do único modo que é possível para a música. Ele substitui a poderosa e eterna associação de ideias a partir de padrões da nature$\mathrm{za}$, na qual as outras artes prosperam. ${ }^{25}$ (SCHENKER, 1968 [1906], p.4).

A presente seção mostra como em Harmonielehre os motivos incorporam o caráter e ânimo antes designados à linguagem ao serem substancializados e antropomorfizados em contextos musicais diversos. Mostra a mudança qualitativa no conceito de repetição: se em Geist ela propiciava a autonomia da música deixando-a órfã da linguagem, em Harmonielehre, ela representa a vitalidade dos motivos, engendrando a própria finalidade do material musical. Em uma seguinte e complementar etapa, esta seção mostra como, a partir do conceito de grau da escala [Stufe], os motivos se fundem com a estruturação harmônica, sendo compreendidos como suas elaborações.

Analisando as transformações do vocabulário de Schenker, Pastille observa que,

[...] em Harmonielehre, ele [Schenker] começa a aceitar o conceito de orgânico, mas não a palavra em si - em todo o livro eu encontrei apenas uma instância da palavra orgânico e uma da palavra organismo. Schenker preferia as palavras

\footnotetext{
24 Original: "[The Geist essay] it anticipates Schenker's life's work to a striking degree [...] It identifies the terrain within which the later theory will operate, reveals the problems to which the later theory will present itself as the solution".

25 Original: "But whence should music take the possibility of associating ideas, since it is not given by nature? [...] The motif, and the motif alone, creates the possibility of associating ideas, the only one of which music is capable. The motif thus substitutes for the ageless and powerful associations of ideas from patterns in nature, on which the other arts are thriving".
} 
biológico [Biologisch] e animalesco [Animalisch] a orgânico [Organisch], e as palavras criatura [Kreatur] e ser vivo [Lebewesen] a organismo [Organismus]. ${ }^{26}$ (PASTILLE, 1984, p.33).

A presença constante de conceitos biológicos e psicológicos ${ }^{27}$ auxilia Schenker na conceituação do motivo. Na seção intitulada "Repetição como um princípio subjacente do motivo",28 este é definido como uma "série de notas recorrente"29 (1968 [1906], p.4). Por meio do processo de repetição, com suas diferentes gamas de variação, o motivo demarca limitando as sucessões de notas. Esses limites implicam não só a sua identificação como material artístico, mas sobretudo a avaliação de um propósito imanente da substância musical que se forma por meio do processo de repetição.

Em suas palavras, "somente a repetição pode demarcar uma série de notas e seu propósito"30 (1968 [1906], p.5, grifo nosso). O termo "propósito" evidencia uma concepção vitalista do material musical, segundo a qual os motivos são lidos como entidades com finalidade própria. Schenker disserta que "devemos nos acostumar a compreender as notas como criaturas. Devemos aprender a assumir nelas impulsos biológicos como os que caracterizam os seres vivos"31 (1968 [1906], p.6, grifos nossos) - e ainda, por extensão, "uma série de notas se torna um indivíduo no mundo da música"32 (1968 [1906], p.6). Os motivos representam, desse modo, uma espécie de substancialização da música, no sentido de concreção, de tornar concreto e material a coisa musical. A teorização do motivo como o dispositivo que eleva a música à categoria de arte é fundamentada na sua projeção como um organismo vivo, uma substância animada, um indivíduo.

A essência do motivo é identificada segundo a média de suas repetições variadas em um processo que remete ao comportamento do ciclo vital: origem - crescimento - reprodução - dissolução. Essa analogia entre motivo e vida é expressa por Schenker da seguinte forma:

26 Original: "Next, in Harmonielehre, he begins to accept the concept of the organic, if not the word itself - in all of Harmonielehre I have found only one instance of the word Organisch and one of Organismus. Schenker preferred the words Biologisch and Animalisch to Organisch, and the words Kreatur and Lebewesen to Organismus".

27 É neste sentido que o musicólogo Nathan Fleshner procura traçar paralelos entre a pesquisa freudiana e a teoria schenkeriana, ambas em pleno desenvolvimento na virada do século XX em Viena. Segundo o comentador, "como Freud, [Schenker] tentou encontrar um processo analítico profundo para compreender a superfície musical: esse processo iria revelar a origem estrutural inconsciente da obra" (2012, p.3). Essa oportuna correlação foi sugerida previamente, mas com menor extensão por alguns outros musicólogos (FORTE, 1959; EYBL, 2006; MORGAN, 2016 [2002], dentre outros). Ela reconhece que ambos os autores são fundadores de uma metodologia analítica baseada na inquirição de processos subjacentes e inconscientes que conduzem o comportamento humano. Em ambos os casos, as metodologias inauguram pensamentos relacionados à noção de estrutura que, por meio de atualizações e correções, impulsionou o desenvolvimento de escolas bastante influentes no decorrer de todo o século XX.

28 Original: "Repetition as the underlying principle of the motif".

29 Original: "A recurring series of tones".

30 Original: "Only repetition can demarcate a series of tones and its purpose".

31 Original: "We should get accustomed to seeing tones as creatures. We should learn to assume in them biological urges as they characterize living beings".

32 Original: "A series of tones becomes an individual in the world of music". 
Na Natureza: impulso procriativo $\rightarrow$ Repetição $\rightarrow$ Tipo individual. Em música, analogamente: impulso procriativo $\rightarrow$ Repetição $\rightarrow$ Motivo individual. ${ }^{33}$ (SCHENKER, 1968 [1906], p.6-7).

O motivo é associado com o sistema tonal, estabelecendo uma relação de interdependência. Schenker pensa um sistema teórico que coaduna a tonalidade como espaço de criação musical respaldado pela natureza, com os motivos, as entidades que nele "habitam". Embora ainda não integradas por uma estrutura global que as unifique, as duas instâncias (motivo/ criatura e tonalidade/ecossistema), mesmo que distintas, influenciam-se mutuamente.

[...] o motivo constitui a única célula seminal da música enquanto arte. Sua descoberta foi de fato difícil. Não menos difícil, no entanto, foi a solução de um segundo problema, a saber, a criação de um sistema tonal em que a associação motívica, uma vez descoberta, pudesse expandir-se e expressar-se. Basicamente, os dois experimentos são mutualmente dependentes: toda a exploração da função do motivo iria, ao mesmo tempo, avançar o desenvolvimento do sistema tonal, e vice-versa, toda progressão do sistema iria resultar em novos caminhos para a associação motívica. ${ }^{34}$ (SCHENKER, 1968 [1906], p.20).

A dicotomia entre motivo (criatura) e sistema harmônico (ecossistema), separados como polos conceituais opostos e complementares, é resolvida com o conceito de Stufe (grau da escala). Desenvolvido em meio às metáforas biológicas, segundo Pastille, é um conceito decisivo na trajetória do organicismo na teoria schenkeriana, apontando para as resoluções das objeções à causalidade delineadas em Geist. Nas palavras do comentador, "a descoberta da Stufe como uma força ideal abriu a porta para a posterior aceitação do organicismo"35 (1984, p.33, grifo nosso). Ao que se pode acrescentar: abriu também a porta para a reformulação do organicismo já presente em Harmonielehre, das metáforas pontuais para uma visão sistêmico/holística. Segundo Pastille (1984, p.32), é uma descoberta que "proveu à música uma segunda dimensão em adição à horizontal, e, se não estabeleceu a prova do organicismo imediatamente, ao menos reabriu a questão do crescimento orgânico ao criar uma nova direção na qual o crescimento pode ocorrer". ${ }^{36}$

Além de permitir que Schenker pense a causalidade musical não apenas nas dimensões horizontal e vertical, a Stufe é o dispositivo conceitual que inicia a jornada de implementação de um terceiro eixo: a profundidade. Em Harmonielehre, ao mesmo tempo em que nomeia o impulso de verticalização, ela sugere que a causalidade resulta do processo gerativo, remetendo à noção de níveis estruturais elementares e projecionais. O conceito de Stufe

\footnotetext{
33 Original: "In Nature: procreative urge - repetition - individual kind. / In Music, analogously: procreative urge - repetition - individual motif".

34 Original: "Thus the motif constitutes the only and unique germ cell of music as an art. Its discovery had been difficult indeed. No less difficult, however, proved to be the solution of a second problem, viz., the creation of a tonal system within which motivic association, once discovered, could expand and express itself. Basically, the two experiments are mutually dependent: any exploration of the function of the motif would, at the same time, advance the development of the tonal system, and vice versa, any further development of the system would result in new openings for motivic association".

35 Original: "The discovery of the Stufe as an ideal force opened the door to his later acceptance of organicism".

36 Original: "This discovery provided music with a second dimension in addition to the horizontal; and if it did not immediately establish proof of organicism, at least it reopened the question of organic growth by creating a new direction in which growth might occur".
} 
se refere à força harmônica ideal que verticaliza as linhas melódicas ou ainda à "penetração do princípio harmônico na linha horizontal de uma melodia" (SCHENKER, 1968 [1906], p.134).

Na exposição desse conceito, Schenker analisa melodias de cantos gregorianos com polos tonais pouco claros (Fig. 1), compreendendo-as como sucessões de notas "que parecem ter sido postas juntas ao acaso e de modo irracional"37 (1968 [1906], p.134). Note-se que, em sua argumentação, a questão da causalidade novamente entra em jogo, mas, nesse caso, em vez de se referir a princípios filosóficos, pontua objetivamente aspectos técnicos de uma construção musical.

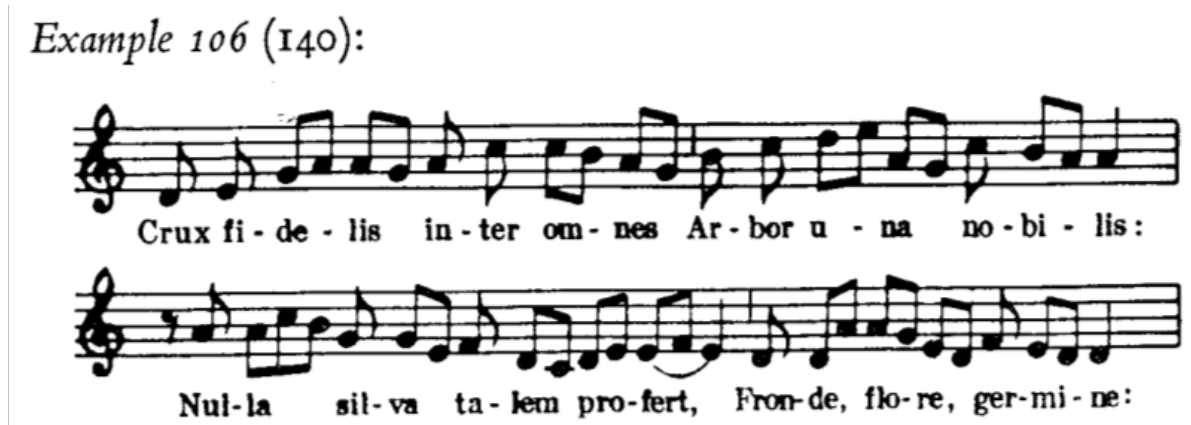

Fig. 1: Hino Crux Fidelis (SCHENKER, 1968 [1906], p.136)

Schenker aponta a dificuldade de projetar tríades sobre este hino, de modo a estabelecer virtuais progressões harmônicas. De fato, neste hino (Fig. 1), os saltos de terça imediatos (precedentes e subsequentes), ou por vizinhança próxima, não reforçam uma concepção harmônico/triádica subjacente que seja simpática às predileções de um ouvido acostumado ao tonalismo. O Sól3 de nes na primeira cadência e o Mi3 de fert na terceira podem até ser lidos como sensíveis, apontando para os polos principais. No entanto, também não apresentam terças imediatas às quais se poderia inferir indubitavelmente acordes de função dominante. Além disso, a irregularidade do agrupamento das notas (12-11-17-12 colcheias por segmento), junto à homogeneidade das figuras rítmicas (45 colcheias e 3 semínimas), sugere um ritmo harmônico irregular e não recorrente. Esses aspectos remetem a uma percepção não acostumada com a sonoridade simultânea de uma tríade: uma característica inerente, como aponta Schenker, ao período pré-contrapontístico. Remetem também a um estado em que a homogeneidade dos elementos dificulta a apreensão das formas e dos percursos. Sobre isso, Schenker (1968 [1906], p.137) argumenta que "dificuldades desse tipo (talvez mais do que qualquer outra razão) podem ter contribuído para a criação de um sistema tonal que facilitasse uma apreensão mais firme e duradoura dessas melodias". ${ }^{38}$

Como contraste, Schenker apresenta a canção folclórica suábia Muss i denn (Fig. 2). Essa melodia reforça uma progressão harmônica por meio de sua métrica regular, sua relativa heterogeneidade rítmica e, acima de tudo, as relações de terça estabelecidas imediatamente

\footnotetext{
37 Original: "To have been thrown together in a haphazard and irrational fashion".

38 Original: "Difficulties of this kind (perhaps even more so than any other reason) may have contributed to the creation of the tonal systems, which facilitated a firmer and most lasting grip on those melodies".
} 
e em vizinhanças próximas. Assim, como projeções da tríade de Sol, o Si3 (c. 1.1) e o Ré4 (c. 2.1) conectam-se ao Sol3 da anacruse: embora sejam notas de maior duração e localizadas nos tempos fortes do compasso, no quesito harmônico, são derivações de Sol3. Em meio a essa reafirmação tonal, dó4 (c. 1.3) e mi4 (c. 1.4.2) formam a tríade de função subdominante. Sua localização entre os eventos que remetem a Sol3 (Si3 e Ré4) implica digressão em relação à projeção da tríade de Sol. A tríade de Dó é, portanto, um breve desvio local encapsulado por um evento de maior abrangência.

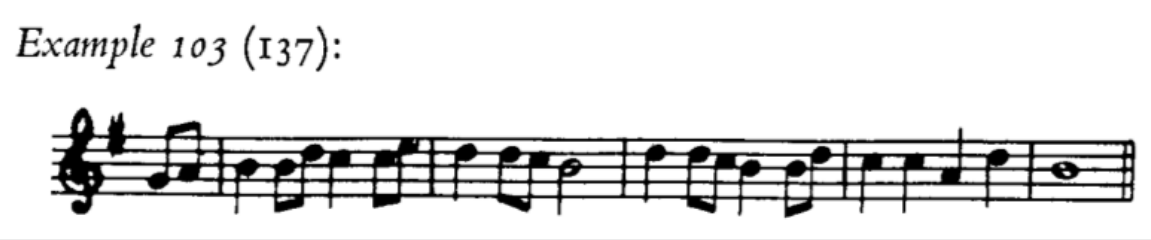

Fig. 2: Canção folclórica suábia Muss i denn (SCHENKER, 1968 [1906], p.133)

A observação da sequência de notas, tomando por princípio a prevalência dos princípios harmônicos implica recorrência, ciclicidade e redundância. Em vez de uma leitura linear, o segmento é compreendido como compactações de eventos de menor abrangência em eventos de maior abrangência. A tonalidade é a chave de leitura e a lei de preferência que permite essa compactação dos eventos musicais. Assim, a sequência temporal das notas é confrontada com a sequência hierárquico/harmônica. Na dimensão da profundidade representeada nesta, ao contrário da dimensão horizontal representada naquela, Ré4 (c. 2.1) vem antes de Dó4 (c. 1.3) - ou, ainda, Ré4 é mais pesado que Dó4, e assim estabelece maior força gravitacional em relação à tônica.

O conceito de Stufe compreende as questões envolvidas nessa descrição. Similar à lógica de que as relações de terças podem remeter à redundância de uma fundamental em seus parciais, o grau escalar (Stufe), em uma janela estrutural mais ampla, é visto como um evento que representa notas inferiores na hierarquia harmônica. É uma representação independente do fator temporal, que pode se dar tanto em um nível próximo (por exemplo, no excerto da melodia folclórica acima) como em nível mais abrangente (por exemplo, em uma sonata inteira). Segundo Schenker (1968 [1906], p.139), "a Stufe afirma seu superior ou mais geral caráter ao comprimir ou resumir o fenômeno individual e incorporar sua unidade intrínseca em uma única tríade". ${ }^{39}$ É, portanto, um conceito que nomeia tanto a percepção da tríade virtual que o ouvido acostumado à sonoridade tonal almeja, quanto a percepção de que essa tríade se sobressai aos outros eventos.

Ainda segundo o autor, "[...] nosso ouvido não perderá a oportunidade de ouvir tais tríades, não importa quão distante nas profundezas de nossa consciência essa concepção possa estar escondida e não importando se no plano da composição ela é ofuscada por relações 
mais óbvias e importantes"40 (SCHENKER, 1968 [1906], p.134, grifo nosso). Remetendo a processos inconscientes que escapam à percepção imediata e objetiva, expressando as "profundezas de nossa consciência", a Stufe é o dispositivo que permite Schenker pensar a teoria da harmonia como "a mais secreta psicologia da música" (1968 [1906], p.153).

Além desses aspectos, a noção de Stufe passa a nomear as relações de forças entre tríades. O processo de tonicalização ${ }^{41}$ se dá quando "o compositor se rende para o impulso da Stufe no âmbito do sistema diatônico de que ela faz parte"42 (1968 [1906], p.256, grifo nosso). No jogo de forças que ela representa, as notas da escala, com seus próprios impulsos vitais e propagações em tríades, almejam tornar-se tônica e adquirem nesse processo seu grau de importância estrutural. Ou seja, a Stufe conceitua a nota da escala não como um evento melódico, mas como um espaço harmônico, um polo tonal que habita conflituosamente um sistema. Nesse conflito, por vezes, ela "usurpa [...] a classe da tônica, sem se importar com o sistema diatônico que ela faz parte"43 (SCHENKER, 1968 [1906], p.256). Em outras palavras, na narrativa organicista de Schenker, a Stufe remete ao impulso da própria natureza que o compositor, "se rendendo para o seu impulso", faz despertar. Um impulso de individuação que habita conflituosamente o sistema diatônico e a partir do qual nascem e se proliferam as figuras musicais de percepção imediata (os motivos).

A substância animada que o motivo incorpora adquire com a Stufe a sua direta contrapartida harmônica. A Stufe é um elemento harmônico que remete diretamente ao processo composicional. O motivo é compreendido a partir de sua associação com a Stufe como "o intérprete do conceito harmônico" (SCHENKER, 1968 [1906], p.211). Com essa compreensão, finalmente na teoria schenkeriana, "[...] harmonia e conteúdo tornam-se [...] [uma situação na qual] o sentimento da Stufe é despertado em nós"44 (1968 [1906], p.212, grifo nosso). Ou seja, a Stufe justifica o motivo em um nível estrutural e permite que ele seja lido não mais como uma série de transformações sem relação com uma determinada harmonia, mas como uma derivação natural da estrutura harmônica. Ela constitui o primeiro passo na trajetória da teoria schenkeriana em direção à reformulação de todos os aspectos musicais a partir de uma concepção holística da estrutura musical. Assim, um motivo de Chopin (Fig. 3), por exemplo, é lido não apenas como um arpejo ascendente seguido de um descendente, mas como uma manifestação do primeiro grau da escala (1^).

\footnotetext{
40 Original: For our ear will miss no opportunity to hear such triads, no matter how far in the background of our consciousness this conception may lie hidden and no matter whether in the plan of the composition it is overshadowed by far more obvious an important relationships".

41 Também denominado inclinação ou modulação passageira.

42 Original: "[...] The composer yields to this urge of the scale step within the diatonic system of which this scale-step forms part [...]".

43 Original: "[...] Usurps quite directly the rank of the tonic, without bothering about the diatonic system, of which it still forms a part".

44 Original: "[...] Harmony and content become one [...] the feeling for the scale step awakes in us".
} 


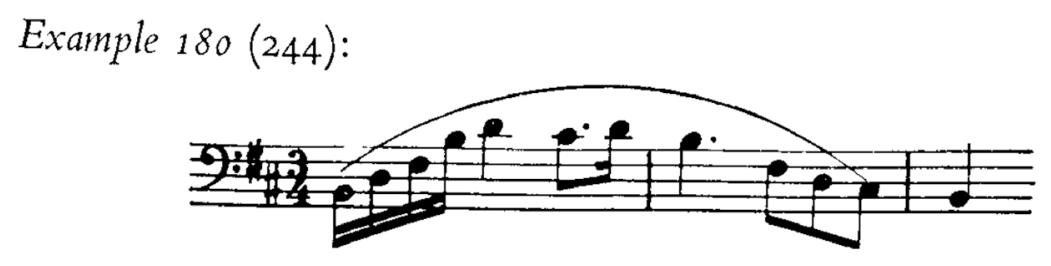

Fig. 3: Motivo inicial do Prelúdio op. 28 n. 6, em Si menor, de Frédéric Chopin (SCHENKER, 1968 [1906], p.211).

Em Harmonielehre, no entanto, as consequências da associação entre motivo e Stufe ainda se encontram em estado incipiente. O percurso para a associação entre esses dois conceitos pode ser visto como um elemento central nos desenvolvimentos posteriores da teoria schenkeriana. Isso porque a Stufe antecipa o conceito de elaboração composicional [Auskomponierung], que primeiramente se relaciona com o conceito de Urlinie e, posteriormente, com o conceito de Ursatz. Ou seja, pode ser rastreada à conceituação da Stufe a ideia de que o acorde é elaborado temporal e espacialmente a partir de princípios da condução de vozes em níveis estruturais. A diferença reside no fato de que, à época em que o conceito de elaboração composicional é formulado, os motivos já são um elemento secundário no discurso sobre a estrutura musical, como mostra a seção seguinte.

\section{A linha derradeira em Kontrapunkt [1910]}

Segundo Pastille e Cadwallader (1992), um evento significativo da transformação do status do motivo na teoria schenkeriana pode ser encontrado na discussão sobre a fluência melódica em Kontrapunkt (1987a [1910], p.94-100). Fluência melódica se refere basicamente à "boa condução de vozes no contraponto estrito, isto é, à movimentação primariamente por graus conjuntos, com saltos cuidadosamente controlados"45 (PASTILLE; CADWALLADER, 1992, p.120). No entanto, o conceito passa a adquirir maiores dimensões na medida em que Schenker analisa linhas melódicas fluentes que subjazem a melodia de fato. É o caso, por exemplo, de sua análise dos primeiros quinze compassos da Suíte Inglesa em Ré menor, de Johann Sebastian Bach (Fig. 13). Essa análise é praticamente restrita à representação gráfica, sendo interessante, portanto, tecer sobre ela alguns comentários.

A linha melódica apresentada por Schenker, em suas palavras, "[...] representa o resultado mais oculto, o produto derradeiro das linhas ascendentes e descendentes"46 (1987a [1910], p.96). Esse recurso analítico propõe uma forma simples de representar a movimentação do complexo de notas de cada compasso. Assim, Lá3 (Fig. 4, C. 1) é a nota em comum que condensa as informações de três arpejos (Fig. 5, c. 1) e das duas funções que esses arpejos exercem (tônica e dominante). ${ }^{47}$ Esse Lá3 também é válido para representar o primeiro compasso da peça, pois sugere um salto relativamente parcimonioso para a próxima nota desta

\footnotetext{
45 "Good voice leading in strict counterpoint, that is, motion primarily by steps, with skips carefully controlled."

46 "[...] Represent the most concealed result, the ultimate product of ascending and descending lines."

47 Mesmo que o VII grau não apresente a nota lá, o conceito de dominante sem fundamental implica a noção de que a nota lá está virtualmente presente.
} 
linha oculta (Fig. 4, Ré4, c. 2), por sua vez representativa das informações do compasso em que se situa (c. 2). O salto entre essas duas notas (Lá3 e Ré4) é preenchido por graus conjuntos descendentes até o seu retorno (Fig. 4, Lá3, c. 5). A continuação desse movimento descendente forma um amplo movimento que engloba e representa as movimentações internas da melodia de fato (Fig. 4, c. 2 até c. 6.1.3).

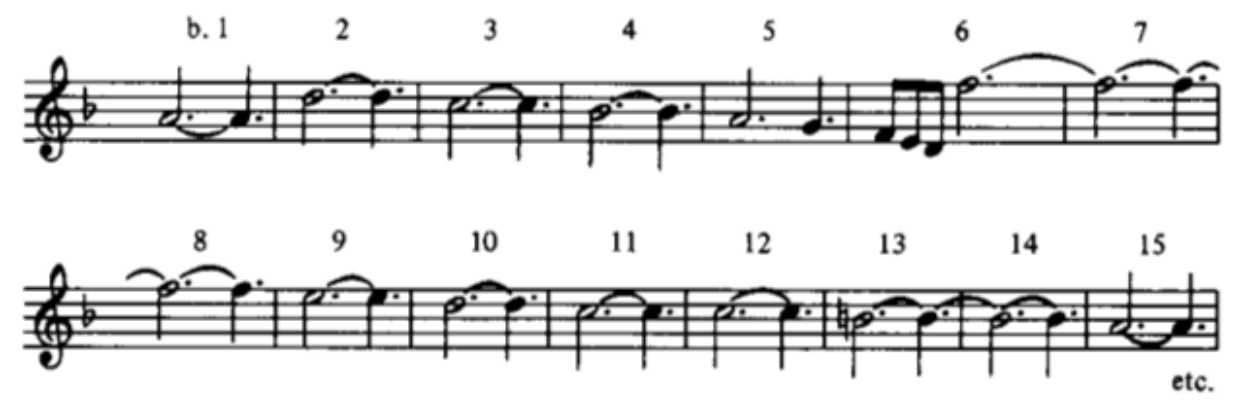

Fig. 4: Linha melódica subjacente aos primeiros quinze compassos da Suíte Inglesa em Ré menor, de Johann Sebastian Bach. (b. refere-se a bar = compasso) (SCHENKER, 2001 [1910], p.96)
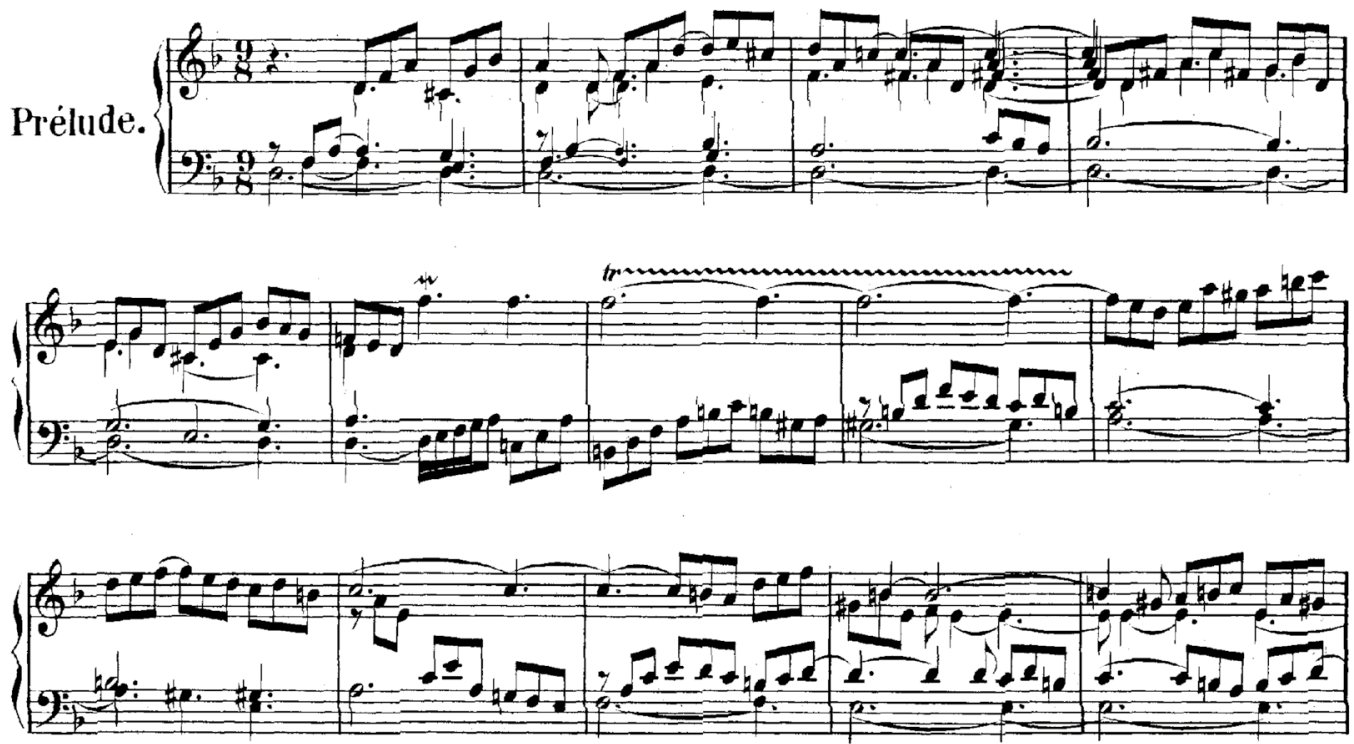

Fig. 5: Excerto da Suíte Inglesa n. 6 em Ré menor BWV 811, de Johann Sebastian Bach, c. 1-14

Lá3 também é válido para representar o primeiro compasso da peça, pois apresenta alto grau de equidistância entre os pontos extremos do segmento (Fig. 4, Ré2 e Fá4, c. 6.1 .3 e c. 6.2). Por extensão, permite ainda a representação de um grande arco formal que encerra apenas no final do segmento com o retorno a Lá3 (Fig. 4, c. 1 a c. 15). Lá3 é, portanto, a representação mais elegante não apenas no âmbito do compasso, mas também no âmbito da conexão das representações de cada compasso em larga escala.

Em sentido similar, Dó4 (Fig. 4, c. 3) representa a função de dominante secundária exercida por Ré7 e, por meio da resolução da tensão, ele se conecta com a terça (Si b 3) do acorde de função subdominante (Fig. 4, Sol menor, c. 4). Mesmo que essas notas estejam esparsas 
na partitura original (Dó4, Fig. 5, 3.1.3, mão direita e 3.3.1, mão esquerda; e Si b 3, c. 4.1, mão esquerda, e 4.3.2, mão direita), para Schenker, elas sobressaem do contexto e estabelecem entre si uma linha independente e virtual. Nesse sentido, é interessante observar como a resolução da dominante (c. 4) é defasada entre as duas mãos, sendo atingida primeiramente na mão esquerda. Mesmo que a resolução na mão direita só aconteça no fim do compasso, a representação da linha melódica superior do compasso 4 como Si b (Fig. 4) denota a influência do contexto harmônico global no entendimento da linha analisada.

Assim, o "produto derradeiro das linhas ascendentes e descendentes" (SCHENKER, 1987a [1910], p.96) é uma espécie de média ou eixo das alturas de um compasso, ao mesmo tempo em que infere uma linearidade entre os eventos a partir das notas mais significativas de uma progressão harmônica. É uma linha melódica abstrata que estabelece relações variadas com o comportamento progressivo da linha melódica de fato e sua disposição formal, oferecendo pontos de referência para possíveis cotejamentos analíticos com os segmentos melódicos da peça.

Outro detalhe da análise de Schenker merece atenção: a representação das colcheias (Fig. 4, c. 6), que estabelece uma fusão entre a linha oculta e as notas da partitura de fato. A função dessa representação é estabelecer o arco formal em que os motivos na mão direita passam para a mão esquerda (Fig. 5, c. 6. 2). Ela aponta o evento que talvez mais salte aos olhos em primeira análise e o que poderia mais interessar em um estudo performático da peça, já que remete diretamente a um gesto mecânico. Além disso, marca o fim de uma locução harmônica (de c. 1 a c. $6: \mathrm{t}-\mathrm{s}-[\mathrm{D}]-\mathrm{s}-\mathrm{\theta} / \mathrm{t}-\mathrm{t}$ ), ${ }^{48}$ o que justifica a conclusão da linha no primeiro grau. Isso não seria possível se fosse mantida a rítmica previamente estabelecida (uma nota por compasso) e tendo-se como requisito o caminho parcimonioso característico de uma "melodia fluente".

No entanto, embora as razões acima justifiquem sua existência, a representação das colcheias (Fig. 4, c. 6) resulta em inconsistência no que se refere ao nível estrutural analisado. Se até o compasso 5 as notas representavam determinada distância da melodia de fato, essa regra é quebrada no compasso 6 , implicando alteração da janela de leitura. A unidade mínima de referência, estabelecida como uma média das movimentações melódicas reais, torna-se subitamente a própria movimentação real que estaria representando. Nessa inconsistência, a partitura é observada com graus de resolução diversos, de acordo com questões pontuais, ad hoc.

De modo similar, é também questionável a segunda representação de Lá3 (Fig. 4, c. 5.15.2). Trata-se de uma nota que aparece apenas uma vez no compasso (Fig. 5, c. 5.3.2), após a vigência de sua representação (Fig. 4, c. 5.2), sendo apenas uma nota de passagem entre a sétima e a quinta do acorde de função $\oslash$ (Dominante da sensível). Por que o autor não ampliou a vigência de si b 3 e incorporou Lá3-Sol3 à figura sequente, grafando tudo em colcheias? Embora se possa argumentar que ele é representativo da função D (dominante), sua escassez de aparições na partitura de fato gera um certo desconforto. Há aqui um conflito entre a representação da média das notas do compasso e a sequência dessas médias. Ou seja, Schenker escolheu representar dois terços do compasso com uma nota sem número

48 Legenda: $\mathrm{t}$ = tônica; $\mathrm{s}$ = subdominante; $\mathrm{D} / \mathrm{t}=$ dominante da sensível com nota pedal na tônica; [D] = dominante secundária. 
de aparições consideráveis em prol da conectividade entre as notas da linha abstrata e da resolução do salto de quarta inicial (Fig. 4, Lá3-Ré4).

O Sol3 de sua análise (Fig. 4, c. 5.3) resolve parcialmente o conflito entre linha abstrata e notas reais gerado a partir da representação desse Lá3 (Fig. 4, c. 5.1). A representação das colcheias (Fig. 4, c. 6.1) é uma consequência da necessidade de representar Sol3 para fazer jus às notas reais do compasso.

Observa-se na análise de Schenker, de Kontrapunkt (Fig. 4), traços da intuição seminal que terá como consequência o desenvolvimento do método schenkeriano. Ao longo de sua produção, Schenker aprimora esse projeto analítico com o intuito de eliminar suas inconsistências e tornar mais clara a representação de suas observações. Assim, a separação dos níveis estruturais (Schichten) se apresenta como uma solução na identificação das janelas de observação referentes a cada nível da estrutura musical (Fig. 6). Supõe-se, nesse sentido, que, em uma possível análise de Schenker em momentos posteriores de sua produção teórica, o autor separaria as colcheias (Fig. 4, c. 6) das outras notas por meio da diferenciação dos símbolos gráficos que as representam (Fig. 6, notas entre c. 5-7). Desse modo, os diferentes níveis estruturais seriam representados em um único sistema, configurando um procedimento que delineia um terceiro eixo analítico: a profundidade - um eixo que se soma à horizontalidade (ritmo/tempo) e à verticalidade (alturas) já presentes na disposição tradicional de uma partitura.

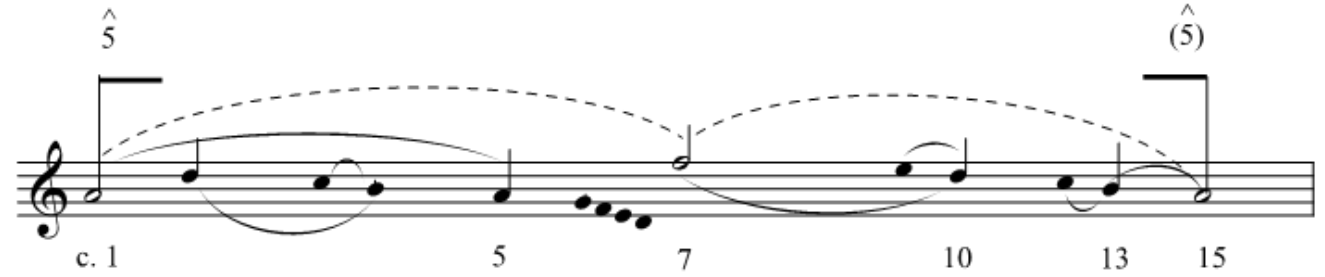

Fig. 6: Reformulação da análise de Schenker com separação de níveis em um único sistema. Elaboração do presente autor.

É proposta assim uma reformulação hipotética ${ }^{49}$ (Fig. 6) da análise de Schenker (Fig. 4), realizada com as ferramentas gráficas desenvolvidas posteriormente, tanto por ele próprio quanto por autores como Salzer (1982 [1954]) e Forte/Gilbert (1982). Nesta inscrição gráfica de um discurso metanalítico, o Lá3 (c. 1) é tido como uma Stufe, representando o quinto grau da Urlinie que se completará apenas no fim do movimento..$^{50}$ Incorpora-se assim a noção de que todo o segmento percorre um caminho de afastamento e retorno à unidade estrutural de origem, ou seja, o grande arco formal já proposto na análise de Schenker (Fig. 4). O trajeto até Fá4 (Fig. 6, c. 7) marca o eixo central do segmento, formado por dois desdobramentos do

49 Realizada não a partir do excerto de Bach, mas da reinterpretação das intuições analíticas que podem ser inferidas da análise de Schenker (Fig. 13). Em outras palavras, é uma reformulação das impressões e compreensões do Schenker, de Kontrapunkt [1910], em vez de uma análise schenkeriana derradeira dos compassos iniciais da Suíte Inglesa BWV 811. Ou seja, o intuito aqui é mais metateórico do que analítico - razão pela qual a contextualização harmônica com o contraponto da linha inferior não foi considerada.

50 A representação completa da Urlinie foge ao escopo da presente discussão, que propõe apenas reformular a análise dos quinze primeiros compassos realizada por Schenker. 
intervalo de sexta, o primeiro ascendente e o segundo descendente. O primeiro desdobramento apresenta uma trajetória formada por dois saltos - Lá3 (c. 1) até o Ré4 subsequente e Lá3 (c. 5) até Fá4 (c. 7) -, enquanto o segundo opera por graus conjuntos descendentes. Nesse sentido, o segmento todo pode ser contemplado como o preenchimento por graus conjuntos de lacunas formadas por saltos de sexta.

O caminho até Ré3 (Fig. 6, c. 6.1.3) é considerado um evento de superfície e pouco influente na estrutura global por refletir as notas reais da partitura em vez do nível profundo que as compreende. O Sol3 (c. 5.3), que na análise de Schenker serve para manter a parcimônia da linha até Ré, perde esse propósito, sendo representado juntamente à linha descendente localizada entre o salto de Lá3 a Fá4. A questão que parece ter levado Schenker a representar essa linha não é aqui considerada: Lá3 representa a função de dominante sem que o fato de sua escassez de aparições gere desconforto.

Lá3 é, principalmente, o quinto grau da Urlinie e, portanto, um polo estrutural () ao qual todos os outros eventos se agregam. Essa é a diferença fundamental entre os dois discursos analíticos. O Schenker de 1910 ainda não havia proposto uma instância estrutural básica para resolver as diversas contradições inerentes ao processo representativo-analítico. Em seu aspecto mais concreto, mais ligado à prática analítica, a Urlinie aparece na teoria schenkeriana como uma regra de preferência: "na dúvida, prefira a Urlinie" - uma regra para todos os casos em que há conflito entre as notas reais e as representações da estrutura.

O aprimoramento da conceituação da linha melódica subjacente é um dos traços mais significativos do desenvolvimento da teoria schenkeriana. Primeiramente chamadas de "resultado mais oculto, o produto derradeiro das linhas ascendentes e descendentes" (1987a [1910], p.96), em Kontrapunkt elas são encaradas justamente assim, como um "produto" palavra que remete à alteridade: ao processamento de um conjunto de dados de modo que se transformem em uma outra coisa. Por outro lado, a partir da década de 1920, as linhas melódicas ocultas são conceituadas como Urlinie (linha primordial/fundamental), sendo encaradas como instâncias que manifestam as linhas melódicas de fato. O conceito de Urlinie surge para nomear uma nova compreensão do processo analítico desenvolvido em Kontrapunkt. A partir dele, compreendem-se esses "resultados ocultos" não mais como linhas inferidas pelo analista a partir da melodia, mas como instâncias geradoras da linha melódica situadas em suas profundezas. ${ }^{51}$ Enquanto as palavras "produto" e "resultado" remetem aos termos de uma equação, a Urlinie remete à primordialidade e à unidade entre as instâncias melódicas. Assim, melodia oculta e de fato passam a ser encaradas como a mesma entidade sistêmica: uma entidade observada em janelas estruturais diferentes, nos níveis superficial, intermediário e profundo.

Outra consequência da mudança na conceituação da linha melódica subjacente é que, a partir do conceito de Urlinie, a dimensão vertical sugerida pelo conceito de Stufe adquire a sua própria horizontalidade. A Urlinie é uma horizontalidade em nível estrutural mais amplo e profundo que não se refere ao evento melódico, mas ao sequenciamento de Stufen. Enquanto a Stufe, com seu "caráter superior e mais geral" (SCHENKER, 1968 [1906], p.139), é uma entidade que representa as manifestações motívicas, a Urlinie representa a junção das

51 Para uma ampla discussão sobre a metáfora da profundidade na musicologia alemã, ver Watkins (2011). 
Stufen no nível da obra. Trata-se de dois conceitos fundamentais no desenvolvimento da teoria schenkeriana que marcam dois estágios do processo de formação da teoria em seu estado derradeiro: a Stufe, que "comprime ou resume o fenômeno individual e incorpora sua unidade intrínseca em uma única tríade"52 (SCHENKER, 1968 [1906], p.139), é sequenciada na Urlinie, "uma sucessão arquetípica dos tons"53 (SCHENKER, 2004 [1921-1923], p. 21). Enquanto o primeiro incorpora o motivo como uma manifestação de suas propriedades harmônicas, o segundo pensa a estrutura global de uma peça como a sucessão dessas entidades harmônico-motívicas.

Uma reflexão conclui esta seção: os gráficos schenkerianos podem ser compreendidos como entidades autônomas que requerem para sua leitura uma atitude hermenêutica e para sua confecção visões originais (pessoais) acerca da obra analisada. Em outras palavras, não são gráficos realizados com a intenção de alto grau de objetividade, mas inscrições gráficas que "incorporam discursos sobre uma peça musical"54 (AGAWU, 1989, p.285). Por meio dessa inscrição, o analista se comunica no mesmo registro escritural, no mesmo meio de comunicação que foi utilizado para confeccionar a obra. A partitura se torna não apenas um meio para estruturar uma composição, mas também um ambiente de construção de discursos. De acordo com a observação de Agawu, não haveria uma análise schenkeriana correta, que seria a única possível para determinada peça (passível, portanto, de automação). Pelo contrário, o discurso que ela incorpora é o resultado de decisões e seleções analíticas acerca do objeto fluido que se situa entre a composição e sua inscrição em um papel ${ }^{55} \mathrm{~A}$ compreensão musical de Schenker, portanto, não é cristalizada em um grafismo hermético de modo autoritário, mas é trabalhada em um ato escritural em que a compreensão analítica é inscrita de modo endógeno ao sistema notacional. Nesta notação analítica sobre uma notação composicional, a intuição do analista adquire um meio (uma mídia) para precisar sua expressão.

\section{A incorporação do motivo na estrutura profunda}

Segundo Pastille e Cadwallader (1992), mudanças substanciais na teoria schenkeriana se dão a partir do momento em que as linhas melódicas ocultas passam a ser encaradas elas próprias como motivos - em novas acepções do termo motivo que o remetem às transformações nos níveis subjacentes. Essa mudança resulta do cotejamento que Schenker realiza entre as linhas melódicas ocultas com as de fato, um processo no qual se observa as interações entre os níveis estruturais da peça. Assim, o nível profundo de uma melodia passa a desempenhar operações de transformação similares às que regem as manifestações

\footnotetext{
52 Original: "The scale-step asserts its higher or more general character by comprising or summarizing the individual phenomena and embodying their intrinsic unity in one single triad".

53 Original: "[...] An archetypal succession of tones".

54 Original: "It embodies discourse about a piece of music".

55 Nas palavras da professora Ilza Nogueira, em sua arguição em minha defesa de doutorado: "A análise schenkeriana é, indiscutivelmente, uma análise 'econômica' que depende do treino do leitor a respeito dos gráficos que representam conceitos implícitos, ir adiante do grafismo até o entendimento do que Schenker quer projetar, refletindo sua genética cultural: a concepção orgânica de uma determinada obra".
} 
em nível superficial. É nesse sentido que, referindo-se à análise de Schenker da Sonata de Beethoven opus 101/II (2015 [1921]), os autores dissertam que,

Primeiramente, ao identificar a atividade motívica nas linhas melódicas fluentes subjacentes à superfície, Schenker expande a questão das relações motívicas para uma nova dimensão. [...] Schenker entende a presença de motivos de alto nível hierárquico como uma força operativa para as relações motívicas da superfície; ele localiza a liberdade das associações motívicas do nível superficial, como postulando um certo grau de necessidade na associação motívica de alto nivel. ${ }^{56}$ (PASTILLE; CADWALLADER, 1992, p.123).

O conceito de motivo é reapropriado para um novo quadro conceitual, no qual ele passa a designar tanto as melodias no nível superficial quanto as operações de transformação a partir da estrutura profunda. Assim, encontram-se nos textos de Schenker, a partir da década de 1920, passagens que aproximam os conceitos de motivo e nível estrutural. O motivo é generalizado para todos os níveis, passando a se referir não apenas às instâncias de imediata percepção ou reconhecimento, mas também às camadas subjacentes e gerativas da estrutura musical. Assim,

Cada nível estrutural carrega consigo seus próprios motivos; a organização e o crescimento específicos desses motivos são paralelos à organização e ao crescimento específicos do nível ao qual pertencem. Quanto mais próximo se encontram da superfície, mais desenvolvidos e variados os motivos serão. ${ }^{57}$ (SCHENKER, 2014a [1925], p.135, grifo nosso).

Além de se referir às transformações intraníveis (no âmbito de um nível estrutural), o motivo passa também a se referir às transformações interníveis (entre níveis diferentes de uma estrutura), denotando os processos dinâmicos e orgânicos de crescimento. Referindo-se aos processos de desenvolvimento de uma Urlinie, Schenker pensa, por exemplo, que "as primeiras etapas da diminuição, os motivos de primeira ordem [...], servem como conexões entre as vozes superiores e intermediárias"58 (2014a [1925], p.123, grifo nosso). Transformações terminológicas como essa evidenciam que as operações nos níveis profundos (ascensão inicial, arpejamento, transferência de registro, elaboração intervalar etc. $)^{59}$ passam a ser tratadas como objeto de primeira relevância no processo analítico, substituindo o lugar de destaque conferido às operações características da análise motívica tradicional (aumentação, diminuição, permutação, transposição etc.). Não se trata, portanto, nesta etapa da teoria schenkeriana, de suprimir completamente a participação dos motivos no processo analítico, mas de compreendê-los sob uma nova perspectiva. É a partir desses processos

\footnotetext{
56 Original: "First, by identifying motivic activity in the melodically fluent lines beneath the surface, Schenker expands the issue of motivic relations into another dimension [...] Schenker sees the presence of higher-level motives as an operating force for the surface motivic relations; he places freedom of motivic association at the surface, while positing a certain amount of necessity in motivic association at the higher levels".

57 Original: "Each structural level carries with it its own motives; the specific organization and growth of these motives parallels the specific organization and growth of the level to which they belong. The nearer they are to the foreground, the more developed and varied the motives will be".

58 Original: "[...] The first stages of the diminution, the motives of the first order [...] Serve as links between the upper and middle voices".

59 Ver Forte e Gilbert (1982).
} 
de transformação, encarados motivicamente, que Schenker observa os crescimentos inter e intraníveis do seu organismo musical.

A reapropriação do termo motivo em um novo quadro conceitual acompanha a vontade do autor de se distanciar das metodologias analíticas a ele contemporâneas e das que o precederam. Seu método afasta-se do que ele descreve criticamente como o ato de "contar ocorrências" realizado pelos "estatísticos do motivo"60 (2004, [1921-1923], p.27). Nesse panorama, a atenção voltada aos motivos no nível da superfície melódica é tida por Schenker como uma forma menor de apreender a obra musical. Assim, nos anos 1920, tornam-se característicos de seu discurso comentários como: "Ao se sentir prazer em meramente reconhecer a recorrência de um motivo determinadas vezes, imagina-se que se está verdadeiramente escutando e sentindo" (2004 [1921-1923], p.27, grifo nosso). Esses reconhecimentos pontuais são opostos por Schenker à "escuta de longo alcance" (2004 [1921-1923], p.27), em que, aproximando-se da escuta dos grandes compositores do passado, o ouvinte estaria "atravessando e pairando sobre os trajetos amplamente planejados"61 (2004 [1921-1923], p.27).

O desejo da percepção sinóptica da peça levará mais tarde ao abandono completo do termo motivo e à sua utilização como um termo pejorativo. Assim, em Der Freie Satz (1979 [1935]), Schenker argumenta que os grandes compositores "não baseiam suas composições em alguma 'melodia', 'motivo' ou 'ideia'. Pelo contrário, o conteúdo é baseado nas transformações e progressões das conduções de vozes a que a unidade não permite nenhuma segmentação ou nomeação de segmentos"62 (1979 [1935], 26-27, grifo nosso). Essa passagem remete ainda à vontade de se afastar de denominações historicamente embasadas e substituí-las por categorias puras e atemporais. Pode ser lida como o marco final da trajetória do motivo na teoria schenkeriana, em que elementos motívicos não apresentam mais uma relação de interconexão com os aspectos estruturais, mas são compreendidos como ramos superficiais sem conexões com a estrutura profunda. Assim, o conceito de diminuição substitui o motivo tanto para denotar a conexão entre níveis estruturais quanto para afastar-se das terminologias correntes.

Em suma, pode-se afirmar que quatro etapas foram percorridas pelo autor em relação ao tópico motivo: 1) motivos como imitações da linguagem, 2) motivos como entidades autônomas, 3) motivos como estruturas e 4) o abandono dos motivos em prol da estrutura global. Uma trajetória progressiva que acompanha o desenvolvimento da noção de profundidade em sua teoria.

60 Na íntegra: "O que não está em disputa, de modo algum, é a facilidade com que o motivo da nossa sinfonia (o Grove o denomina como um motivo 'agradável'; e com que frequência os estatísticos do motivo gostam de contar suas ocorrências) é apreendido, ganhando a simpatia da audiência em sua primeira aparição". Original: "What is not in dispute, at any rate, is the ease with which the motive of our symphony (Grove calls it an 'agreeable' motive; and how often do motive statisticians enjoy counting up its occurrences) is grasped, gaining the audience's affection at its very first appearance".

61 Original: "Merely by taking pleasure in recognizing the motive as it recurs so many times, one imagines that one is actually hearing and feeling [...]How blissful would the listener certainly feel if he could share the master's long-range hearing, traversing and soaring over the broadly planned paths! If only he could!".

62 Original: "Great composers trust their long range vision. For this reason they do not base their compositions on some 'melody', 'motive' or 'idea.' Rather, the content is rooted in the voice leading transformations and progressions whose unity allows no segmentation or names of segments". 
A trajetória do motivo na teoria schenkeriana é lida pelo musicólogo Richard Cohn (1992) segundo o diálogo de dois paradigmas: o do conflito construtivo e o da unidade pura. $O$ primeiro entende o conflito entre o material musical e a estrutura tonal de maneira dialética. O segundo, a noção de elaboração composicional a partir da unidade estrutural, de maneira hierárquica e gerativa. Ambos estão presentes no discurso schenkeriano e em sua posterior replicação por outros autores. Cohn compreende que boa parte da pesquisa de influência schenkeriana em seu contexto acadêmico (nos anos 1990) voltara-se para o primeiro desses paradigmas - um demonstrativo da atitude pragmática no procedimento analítico em voga, já que pressupõe a demonstração exata nos eventos de superfície das especulações estruturais e o cotejamento dessas instâncias. Em contrapartida, argumenta que o paradigma da unidade pura é o que melhor representa a postura do próprio Schenker, remetendo ao seu ideário organicista e metafísico, no qual a estrutura abstrata se impõe à frente da realidade sensível. Assim, segundo Cohn, o entendimento da teoria schenkeriana, sob a ótica do primeiro paradigma, corre o risco de estabelecer anacronismos, o risco de projetar a postura e o ethos acadêmico recente para um diferente contexto epistemológico.

Pode-se afirmar que há uma transição entre os dois paradigmas na teoria schenkeriana. Uma transição paralela à trajetória aqui delineada do estatuto do motivo: à medida que o termo vai sendo abandonado no repertório conceitual de Schenker, o conflito construtivo entre estrutura e manifestações de superfície é substituído pela visão sinóptica e serena de uma unidade pura, expressa no conceito de Ursatz. Nesse panorama, o caráter sistêmico vai aos poucos se tornando uma constante do discurso schenkeriano. Como consequência, as noções de relações intra e interníveis, sub e supersistemas, hierarquias, processos de transformação etc. tornam-se cada vez mais recorrentes. A análise dos motivos é substituída por um método que fornece um meio de cotejamento entre os níveis das estruturas musicais e que procura descrever o próprio ato criativo, sua metafísica e seus processos inconscientes. O desenvolvimento das noções sistêmicas na teoria schenkeriana é paralelo à incorporação do discurso organicista, na medida em que o autor passa a entender cada vez mais o ato criativo como um desvelamento e uma elaboração das características imanentes da semente musical: a Ursatz.

Tangencialmente a esses desenvolvimentos, o discurso organicista também passa por algumas adaptações e transformações. O "impulso procriativo", que em Harmonielehre se referia às repetições variadas do motivo e às transformações dos fenômenos da superfície musical, passa a se referir às elaborações das linhas subjacentes. Em uma análise, por exemplo, Schenker comenta que "é imediatamente evidente que a Urlinie tenha a forma do que é em essência um motivo de três notas, de quem o impulso reprodutivo [...] dá vida a incontáveis repetições"63 (2004 [1921-1923], p.34, grifo nosso). Mais tarde, esse impulso procriativo passa a se referir não mais a aspectos localizáveis do processo composicional, mas aos fundamentos da teoria por meio do "acorde da natureza".

63 Original: "It is immediately evident here that the Urlinie has the form of what is in essence a three-note motive, whose reproductive urge (see Harmonielehre, pp. $4 \mathrm{ff} / \mathrm{pp} .4$ - 5) gives birth to countless repetitions". 
A estrutura fundamental [Ursatz] nos mostra como o acorde da natureza torna-se vivo por meio do poder vital natural. Mas o poder primal deste estabelecido movimento deve crescer e viver sua própria e completa vida: o ímpeto de vida que ambiciona completar-se com o poder da natureza. ${ }^{64}$ (SCHENKER, 1979 [1935], p.25, grifo nosso).

Uma concepção que apresenta também traços diretamente teológicos em passagens como esta:

Entre a estrutura fundamental e a superfície, manifesta-se uma relação como a sempre presente e interacional relação que conecta Deus à criação e a criação a Deus. Estrutura fundamental e superfície representam, nos termos desta relação, o celestial e o terrestre em música. ${ }^{65}$ (SCHENKER, 1979 [1935], p.160).

Em suma, no estágio final da teoria schenkeriana, o motivo já não é mais encarado como o dispositivo segundo o qual a música é elevada à categoria de arte, como expresso em Harmonielehre. A arte musical passa a ser vista como o resultado da elaboração do "acorde da natureza". Não se trata mais de emular os modos de representação das outras artes para validar a música: ela passa a representar a si mesma na medida em que é um organismo autônomo e autorreferente. Resolve-se, assim, a questão colocada em Harmonielehre: o motivo, como instância propiciadora da associação de ideias, reformulado pelo termo diminuição, passa a ser visto como a manifestação fenomênica de uma estrutura que o compreende e o antecede.

A Ursatz estabelece a premissa de uma estrutura que resulta da confluência entre o acorde da natureza, imutável e extra-humano, com o artifício contrapontístico, que o insere na temporalidade e no movimento dialético do ser humano. A partir dessa premissa, a música é compreendida em uma imagética da profundidade, em que o motivo passa a ser denominado como diminuição para denotar sua conexão com os níveis subjacentes. Já não se associam ideias por meio dele: a entidade musical que ele representava é deslocada de um fenômeno identificável e visível para um processo orgânico em que as "criaturas" são meras expressões no nível superficial de eventos subjacentes. Nesse ideário organicista, o processo vital, antes identificado por repetições variadas dos motivos, adquire agora caráter sistêmico: suas partes são expressões do todo e o todo é mais do que a soma das partes. Em outras palavras, no estágio final da teoria schenkeriana, não se trata mais de compreender as entidades individuais, mas de compreender a entidade sistêmica global e o seu processo gerativo.

\footnotetext{
64 Original: "The fundamental structure shows us how the chord of nature comes to life through a vital natural power. But the primal power of this established motion must grow and live its own full life: that which is born to life strives to fulfill itself with the power of nature".

65 Original: "Between fundamental structure and foreground there is manifested a rapport much like that ever-present, interactional rapport which connects God to creation and creation to God. Fundamental structure and foreground represent, in terms of this rapport, the celestial and the terrestrial in music".
} 


\section{Considerações finais}

A partir de textos do próprio Schenker e de comentadores de sua obra, o presente artigo reuniu momentos significativos da trajetória da teoria schenkeriana, oferecendo uma base para a sua compreensão em um registro histórico-epistemológico. Teve como intuito ampliar o entendimento da metodologia schenkeriana ao apresentá-la como uma trajetória complexa e contraditória, em vez de um sistema teórico-analítico consolidado. Ressaltou as questões filosóficas que tangenciam o discurso sobre a música, apontando sempre a interdependência dessas instâncias.

Em suma, o presente artigo demonstrou a interdependência das transformações do organicismo e do conceito de motivo na produção teórica de Schenker. A aceitação progressiva da ideia de organismo musical - passando pela rejeição completa em Geist (1895); a incorporação parcial em Harmonielehre (1906); até sua plena incorporação em Der Freie Satz (1935) - é acompanhada de transformações no modo de pensar o motivo, este aspecto técnico da construção musical - em Geist, relacionado à linguagem; em Harmonielehre, como criatura com impulsos vitais; e, a partir dos anos 1920, como uma manifestação fenomênica na superfície de uma movimentação profunda e essencial: a Urlinie e, posteriormente, a Ursatz. Essa interdependência de aspectos técnicos e imagético-filosóficos é representativa da complexa concepção musical que Schenker desenvolveu ao longo dos anos: uma concepção que vai muito além da criação de um método analítico.

Apontando para além do escopo deste trabalho, é importante considerar que a idealização de uma instância virtual, que se atualiza em obras heterogêneas, apresenta diversas implicações problemáticas no amálgama ético-estético de Schenker. No cerne dessas questões está uma defesa do sistema tonal em detrimento das inovações musicais de seu tempo, uma postura rigidamente conservadora em oposição ao vanguardismo que se desenvolveu no início do século XX. Nesse sentido, acredita-se que a compreensão das problemáticas inerentes à adaptação do método schenkeriano ao repertório pós-tonal ganha com o levantamento aqui realizado uma fonte para diversas reflexões. ${ }^{66}$

No entanto, o conservadorismo estético não deve se confundir com o frescor e a modernidade que sua metodologia analítica oferece: um modelo gerativo que possibilita o cotejamento analítico a partir de uma estrutura imutável, prescindindo de estratégias ad hoc. Assim, o artigo busca fomentar também o cotejamento da teoria schenkeriana com outras estruturas de pensamento que se desenvolveram ao longo do século $\mathrm{XX}$, como o estruturalismo, a linguística, o pensamento sistêmico, dentre outros. ${ }^{67}$ 


\section{Referências Bibliográficas}

AGAWU, Kofi. Schenkerian Notation in Theory and Practice. Music Analysis, v. 8, n. 3, p. 275-301, 1989.

BOUCQUET, Kristof. Schenker and Schoenberg revisited. Revue Belge de Musicologie, v. 59, p. 193-203, 2005.

COHN, Richard. Schenker's Theory, Schenkerian Theory: Pure Unity or Constructive Conflict? Indiana Theory Review, n. 13, v. 1, p. 1-19, 1992.

COHN, Richard; DEMPSTER, Douglas. Hierarchical Unity, Plural Unities. In: BERGERON, Katherine; BOHLMAN, Philip V. (ed.). Disciplining Music. Chicago: Chicago University Press, 1992. p. 156-181.

COOK, Nicolas. The Schenker project: Culture, Race, and Music Theory in Fin-de-siècle Vienna. Oxford: Oxford university press, 2007.

FINK, Robert. Going flat: Post-Hierarchical Music Theory and the Musical Surface. In: Rethinking Music. Ed. COOK, Nicholas and EVERIST, Mark, Oxford: Oxford University Press, 2001.

FLESHNER, Nathan. The Musical Psyche: Interactions Between the Theories of Heinrich Schenker and Sigmund Freud. Tese (Doutorado em Música) - Department of Music Theory, Eastman School of Music, University of Rochester, Rochester, 2012.

FORTE, Allen. Schenker's conception of music structure. Journal of Music Theory, v. 3, n. 1, p. 1-30. 1959

FORTES, Rafael. A estrutura orgânica da música na teoria schenkeriana. Tese (Doutorado em Música). Programa de Pós-Graduação em Música, Centro de Letras e Artes, Universidade Federal do Estado do Rio de Janeiro, Rio de Janeiro, 2020a.

FORTES, Rafael. Estratégias de expansão da Teoria Schenkeriana a partir da música de Igor Stravinsky. Debates Unirio, n. 24, p.74-118, out. 2020b.

KORSYN, Kevin. Schenker's organicism reexamined. Intégral, v. 7, p. 82-118, 1993.

MORGAN, Robert. Music theory, analysis and society: selected essays. London; New York: Routledge, 2016. 
PASTILLE, William. Heinrich Schenker: anti-organicist. 19th-Century Music, v. 8, n. 1, p. 2936, 1984.

PASTILLE, William. Schenker's value judgments. Journal of the Society of Music Theory, v. 1, n. 6, 1995.

PASTILLE, William; CADWALLADER, Allan. Schenker's High-level motives. Journal of Music Theory, v. 36, n. 1, p. 119-148, 1992.

ROTHSTEIN, William. The Americanization of Heinrich Schenker. In: Schenker Studies. Ed. Hedi Siegel, New York: Cambridge Univ. Press, p. 193-203, 1990.

SCHENKER, Heinrich. Harmony. Chicago: Chicago university Press, 1968 [1906].

SCHENKER, Heinrich. Five Graphic Music Analysis. New York: Dover, 1969 [1932].

SCHENKER, Heinrich. Free composition. New York: Schimmer Books, 1979 [1935].

SCHENKER, Heinrich. The spirit of musical technique [Der Geist der Musikalischen Technik, 1895]. Trad. William Pastille. In: Heinrich Schenker: anti-organicist. 19th-Century Music, v. 8, n 1, p. 29-36, 1984 [1895].

SCHENKER, Heinrich. Counterpoint: a Translation of Kontrapunkt. New York: Schimmer Books, 1987a [1910]. v. 1.

SCHENKER, Heinrich. Counterpoint: a Translation of Kontrapunkt. New York: Schimmer Books, 1987b [1922]. v. 2.

SCHENKER, Heinrich. Der Tonwille: pamphlets in witness of the immutable laws of music. Oxford: Oxford University Press, 2004 [1921-1923]. v. 1, issues 1-5.

SCHENKER, Heinrich. Der Tonwille: pamphlets in witness of the immutable laws of music. Oxford: Oxford University Press, 2005 [1923-1924]. v. 2, issues 6-10.

SCHENKER, Heinrich. The decline of the art of the composition: a Technical-Critical Study. Music Analysis, v. 24, n. 1/2, p. 33-129, 2005 [1905].

SCHENKER, Heinrich. The spirit of musical technique [Der Geist der Musikalischen Technik, 1895]. Trad. William Pastille. In: COOK, Nicolas. The Schenker project: Culture, Race, and Music Theory in Fin-de-siècle Vienna. Oxford: Oxford university press, 2007 [1895]. p. 319332. 
SCHENKER, Heinrich. The Masterwork in Music. Ed. William Drabkin. New York: Dover, 2014a [1925]. v. 1.

SCHENKER, Heinrich. The Masterwork in Music. Ed. William Drabkin. New York: Dover, 2014b [1926]. v. 2.

SCHENKER, Heinrich. The Masterwork in Music. Ed. William Drabkin. New York: Dover, 2014c [1930]. v. 3.

SCHENKER, Heinrich. Piano sonata in A major, op. 101: Beethoven's last piano sonatas, an edition with elucidation, volume 4. Trad. John Rothgeb. Oxford: Oxford University Press, 2015 [1921].

SOLIE, Ruth. The Living Work: Organicism and Musical Analysis. 19th-Century Music, n. 4, v. 2, p. 147-156, 1980.

WATKINS, Holly. Metaphors of Depth in German Musical Thought (from E.T.A. Hoffman to Arnold Schoenberg). Cambridge: The Cambridge University Press, 2011.

WATKINS, Holly. Toward a post-humanist organicism. Nineteenth-Century Music Review, 14, p. 93-114, 2017.

WATKINS, Holly. Musical vitalities: ventures in a biotic aesthetics of music. Chicago: The University of Chicago Press, 2018. 